\title{
Aging effects on joint proprioception: the role of physical activity in proprioception preservation
}

\author{
Fernando Ribeiro • José Oliveira
}

Received: 14 May 2007 / Accepted: 29 July 2007 / Published online: 7 August 2007

(C) EGREPA 2007

\begin{abstract}
Throughout the human life span the functions of several physiological systems dramatically change, including proprioception. Impaired proprioception leads to less accurate detection of body position changes increasing the risk of fall, and to abnormal joint biomechanics during functional activities so, over a period of time, degenerative joint disease may result. Altered neuromuscular control of the lower limb and consequently poor balance resulting from changes in the proprioceptive function could be related to the high incidence of harmful falls that occur in old age subjects. There is evidence of proprioception deterioration with aging. Regular physical activity seems to be a beneficial strategy to preserve proprioception and prevent falls among older subjects. Some studies have demonstrated that the regular physical activity can attenuate age-related decline in proprioception. This paper reviews the evidence of age effects on joint proprioception. We will discuss the possible mechanisms behind these effects and the role of regular physical activity in the attenuation of age-related decline in proprioception.
\end{abstract}

Keywords Aging · Proprioception · Physical activity

\section{Introduction}

Proprioception was originally defined by Sherrington in 1906 [60] as "the perception of joint and body movement as well as position of the body, or body segments, in

F. Ribeiro $(\bowtie) \cdot J$. Oliveira

Research Centre in Physical Activity, Health and Leisure,

Faculty of Sport, University of Porto,

Rua Dr. Plácido Costa 91,

4200-450 Porto, Portugal

e-mail: fisiofernando@gmail.com space". At present, proprioception can be defined as the cumulative neural input to the central nervous system from specialized nerve endings called mechanoreceptors. The mechanoreceptors are located in the joint, capsules, ligaments, muscles, tendons, and skin [15, 77]. Proprioception is generally assessed by measuring both joint position sense (JPS) and the sense of limb movement [25]. JPS determines the subject's ability to comprehend a presented joint angle and then, once removed, actively or passively reproduce the same joint angle [57]. Sense of limb movement determines detection of passive motion of the limb [25]. Both components of proprioception are important for the generation of smooth and coordinated movements, maintenance of normal body posture, regulation of balance and postural control, and motor learning and relearning $[52,73]$. This importance was demonstrated by Ghez and Sainburg [21] and Ghez et al. [22] using deafferented patients. Their data showed that without proprioception, the onset of movement is delayed and trajectory formation is impaired and highly inaccurate.

Motor coordination and balance are abilities that decline during the aging process, at least partially, by the deterioration of proprioception [11, 30, 49, 51, 63]. The somatosensory system and, specifically, the proprioceptive system, are critically involved in the sensory control of balance. Colledge et al. [17] studied the relative contributions of vision, proprioception, and vestibular system to the balance in different age groups. They found that all age groups were more dependent on proprioception than on vision for the maintenance of balance. Thus, impaired proprioception could be a contributing factor to falls. Mion et al. [42] identified impaired proprioception as a contributing factor to falls among patients in a rehabilitative setting. Moreover, Camicioli et al. [13] showed that the disruption of proprioceptive input was the most important 
determinant of quantitative balance performance in subjects older than 80 years. Decline in lower limb proprioception has been linked to balance problems found in the elderly $[26,34,36,80]$, which have, in turn, been associated with the higher incidence of falls $[35,48,64,72]$. Falls not only lead to subsequent personal and social consequences of injury and loss, but are also a major cause of death in older people. So, decline in proprioception with aging could greatly influence balance, increasing the susceptibility to falls. Besides that, a decrease in proprioception could lead to abnormal joint biomechanics during functional activities such as walking so, over a period of time, degenerative joint disease may result [62]. Therefore, it might be important to develop and implement strategies to attenuate the age-related decline in proprioception. Regular physical activity could be an efficient tool in the preservation of proprioception in old age subjects.

The aims of the present review are to report and discuss (1) the aging effects on joint proprioception, (2) the mechanisms behind these effects, and (3) the role of regular physical activity in the attenuation of age-related decline in proprioception.

\section{Evidence of proprioception deterioration with aging}

The actual knowledge about age effects on proprioception is based on cross-sectional studies comparing proprioception in different age groups. Those studies assessed proprioception by measuring JPS and/or the sense of movement, but the methodology used was different between studies. It is important to note that, although using different methodologies, the sense of results led to similar conclusions.

The first studies regarding the effects of aging on proprioception were conducted by Kokmen et al. [32] and Barrack et al. [3, 63]. Barrack et al. [3], who investigated the knee joint, concluded that young members of a professional ballet company had significantly better threshold of perception of joint motion than a healthy, active agematched control group. Skinner et al. [63] investigated the effect of aging on knee proprioception under passive movement (threshold of detection of joint motion and the ability to reproduce passive knee positioning) and observed that older subjects had poorer proprioception in both tests compared to younger subjects.

In the same way, Kaplan et al. [30] assessed the agerelated changes in proprioception using two techniques that required active movement (ipsilateral and contra-lateral active repositioning) and found that older subjects had reduced proprioception compared to younger subjects. Indeed, several studies showed a relationship between aging and decline in several aspects of proprioceptive sensitivity, namely a decrease in joint position sense and an increase in movement detection threshold. The lower limb, knee joint position sense [6, 27, 30, 37, 49, 51], and ankle joint position sense $[41,55,76,82]$ are negatively affected by aging. Similarly, in the upper limb, a decline in elbow [56] and finger [19] joint position sense was observed. Movement detection thresholds increased with advancing age, as shown by the results conducted in the knee $[5,63$, 81], ankle [23, 71], and metacarpophalangeal and metatarsophalangeal joints [32].

For ankle position sense Robbins et al. [55] described an age-related decrease of about $3^{\circ}$ (angular error of estimation increased from $3.418^{\circ}$ in the young adults to $6.548^{\circ}$ in the elderly). Similarly, Sung You [82] found differences of $47.5 \%$ in the joint ankle reposition between young (median age: 22.2 years) and aged (median age: 73.1 years) subjects. Barrack et al. [4] estimated this reduction in about $6.54^{\circ}$. Yan and Hui-Chan [81] showed that the joint detection threshold was 50\% higher in older subjects (aged 5777 years) than in younger subjects (aged 25-35 years) for both knee extension and flexion movements.

\section{Mechanisms of proprioception deterioration with aging}

Proprioception involves central and peripheral components. At the peripheral level, the construction of proprioception is based on the cumulative neural input from mechanoreceptors (articular, muscular, and cutaneous receptors). Several studies analyzed the relationship between the aging process and structural modifications within articular $[2,45]$ and cutaneous $[8,10,16,29,75]$ receptors, which can be found in literature. No study was found that examined age-related changes in the Golgi tendon organ. The present review is focused on muscle spindles because it is the major mechanoreceptor involved in proprioception [39, 53, 54] and because the proprioception changes induced by physical activity seem to be related at peripheral level with muscle spindle adaptations. The central component involves internal feedback loops that transmit information between and within sensory and motor areas [39, 44].

Advancing age causes a decline in proprioception involving both central and peripheral level. At the peripheral level, studies using animals and humans showed anatomical and physiological age-related changes in muscle spindle resulting in muscle spindle decline: a study using rats described an age-related decrease in the dynamic response of the muscle spindle primary afferents to ramp stretch [43]; structural changes of the muscle spindle can be seen in decreases in the total number of intrafusal muscle fibers and nuclear chain fibers per spindle, and increases in spindle capsule thickness [31, 33, 43, 69]; Swash and Fox [69] suggested that these spindle modifications may be the 
result of denervation, because spherical axonal swellings, expanded motor end plates, and group denervation atrophy can also be observed on skeletal muscle; and, Burke et al. [12] found a $30 \%$ reduction in the vibration induced inhibition of the stretch reflex because of aging, suggesting differences in muscle spindle functioning at the spinal level (deterioration of spinal presynaptic inhibition pathways). The conclusions drawn from these studies suggest that proprioception decreases with aging is in part because of changes in muscle spindle function. In addition to that, advancing age leads to deficits in the processing of sensory input (myelin abnormalities, axonal atrophy, and declined nerve conduction velocity) $[7,24,59,74]$ and neuromuscular performance decline. It has been shown that the older adult has fewer, but on average larger and slower motor units, resulting in motor unit reorganization $[9,14,40,65$, 66]. Therefore, this age-related alteration of the number and function of motor units have profound implications in muscle force production and control. This lack of control has also repercussions in proprioceptive ability.

At the central level, central somatosensory pathways conductive function is affected by normal aging [70]. Aging induces progressive loss of the dendrite system in the motor cortex [47, 58], losses in the number of neurons and receptors, and neurochemical changes in the brain [38, 50, 68]. Age-related changes in spindle sensitivity can result from supraspinally mediated changes in the gamma drive to the spindles themselves; changes in the "set" of muscle spindles will have a direct effect on sensitivity [46].

The relative contribution of the central and peripheral level is not established, but it is reasonable to expect that the decline in proprioception found in old age subjects could be related to both central and peripheral changes. However, previous studies [26, 67] suggested that older adults may compensate for deteriorated proprioception (peripheral inputs) by enhancing sensitivity of the central encoding of sensory consequences (central inputs), thereby reducing perceptual proprioceptive errors during balance control.

\section{The role of physical activity in proprioception preservation during aging}

Throughout this review, it has been widely reported that proprioception declines during aging process. Few studies have been conducted to examine the effects of regular physical activity on proprioception preservation during aging.

It is interesting to note that Pickard et al. [52] did not find significant differences when comparing the hip joint position between sedentary young subjects and active aged subjects (mean age: $75 \pm 6$ years), that practiced physical activity 10 (range 3 to 20 ) hours per week. The authors justified the lack of differences between subjects because the aged group was physically active. However, the authors did not compare sedentary aged subjects with active aged subjects, it is impossible to affirm that the lack of significant changes between young and aged subjects is because of the increased physical activity.

Proprioception may be influenced by the level of regular physical activity. Based on this, Petrella et al. [51] designed a study to investigate knee joint proprioception among young volunteers and active and sedentary elderly volunteers. Knee joint proprioception was measured through reproduction of static knee angles using an electrogoniometer. Sixteen young subjects (age range, 19-27 years) and 24 elderly subjects (age range, 60-86 years) participated in the study. The elderly group was separated into active and sedentary subgroups based on their level of activity during the past year. Significant differences were observed between young (mean, $2.01 \pm 0.46^{\circ}$ ) and active old (mean, $3.12 \pm 1.12^{\circ} ; P<0.001$ ), young and sedentary old (mean, $\left.4.58 \pm 1.93^{\circ} ; P<0.001\right)$, and active old and sedentary old $(P<0.03)$. The authors concluded that proprioception is diminished with age and that regular activity may attenuate this decline.

Gauchard et al. [20] investigated the effects of different types of exercise on postural control and balance of aged individuals and concluded that the proprioception can be "trained" and that regular exercise of proprioceptive nature might be beneficial to retain or regain balance. These findings were corroborated by Tsang and Hui-Chan [73]. The authors demonstrated that long-term (mean Tai Chi experience $10.1 \pm 9.5$ years) Tai Chi, a Chinese mind-body exercise that puts a great emphasis on the exact joint position and direction, practitioners had improved knee joint proprioception.

The exact mechanism by which the exercise improves joint proprioception remains to be clearly understood. However, several hypotheses can be provided from the best evidence available. Being central and peripheral levels involved in proprioception, it is not surprising that the explanations for the improvement in proprioception, because of physical activity, involve both components.

Peripheral level improvements in proprioception were linked to alterations in muscle spindle. There is no evidence that training changes the number of mechanoreceptors [1], but there is evidence that training induces morphological adaptations in the major mechanoreceptor involved in proprioception, the muscle spindle. Training can induce muscle spindle adaptations at a microlevel, the intrafusal muscle fibers may show some metabolic changes, and at a more macro level, the latency of the stretch reflex response decreases and the amplitude increases [28]. 
Physical activity improving muscle strength can also improve proprioception. The improvement in muscle strength with exercise might yield better control of movement, which, as a consequence, could enhance joint proprioception under weight bearing conditions [51].

At a central level, physical activity might modify proprioception by modulating the mechanoreceptor gain and inducing plastic changes in the central nervous system. Muscle spindle is the one mechanoreceptor whose gain can be modulated by the central nervous system. The gain is the input-output relationship of any receptor and can be defined as receptor output firing rate divided by the magnitude of the input stimulus [1]. In fact, proprioception can be improved through increased output of the muscle spindles through the so-called $\gamma$ route during voluntary movement. Increased muscle spindle output through the $\gamma$ route may occur during exercise, to enhance joint proprioception by facilitating its cortical projection. In this way, repeated practice of a motor skill is thought to increase muscle spindle output, which could bring about plastic changes in the central nervous system, such as an increased strength of synaptic connections and/or structural changes in the organization and number of connections among neurons [61]. Indeed, repetitive afferent inputs from the mechanoreceptors could modify the cortical maps of the body over time. Plastic changes in the cortex can be induced by repeated positioning of body and limb joints in specific spatial positions as demanded by exercise [73]. Regular physical activity over time can increase cortical representation of the joints leading to enhanced joint proprioception.

Liu et al. [33] examined myosin heavy chain protein content of the spindle fibers and identified that three myosin heavy chain proteins had modified expression in aged muscle spindles when compared to those from young subjects. It is interesting to note that similar myosin heavy chain protein adaptations were found in rats in response to hind-limb unloading [18] and denervation [78, 79]. The loss of nuclear chain fibers may impair the static sensitivity of the spindle and ultimately the ability to correctly interpret muscle length [33]. Future research in old age subjects is needed to determine the possible influence of physical activity in myosin heavy chain protein content of the spindle fibers, and the relationship between improvement in myosin heavy chain protein content and proprioception.

\section{Summary}

It seems to be consensual and well established that proprioception diminishes with aging. Our review has highlighted the evidence that aging has deleterious effects on joint proprioception. The physiologic mechanisms behind the proprioception deterioration with aging involve central and peripheral components. Regular physical activity seems to have a role in the preservation of proprioceptive function, but more studies are needed to clearly ascertain this positive effect. Moreover, it is not clearly understood which mechanisms are responsible for proprioception changes induced by regular physical activity. Explanations are given involving central and peripheral components; however, it seems reasonable to expect that changes in the proprioceptive system because of regular physical activity involve both components. Future research should be conducted to clearly respond to the following questions: (1) What types of exercise have better results in the preservation of proprioception during aging? (2) Which mechanisms better explain old age subject's proprioception improvements induced by physical activity?

\section{References}

1. Ashton-Miller JA, Wojtys EM, Huston LJ, Fry-Welch D (2001) Can proprioception really be improved by exercises? Knee Surg Sports Traumatol Arthrosc 9(3):128-136

2. Aydog ST, Korkusuz P, Doral MN, Tetik O, Demirel HA (2006) Decrease in the numbers of mechanoreceptors in rabbit ACL: the effects of ageing. Knee Surg Sports Traumatol Arthrosc 14 (4):325-329

3. Barrack RL, Skinner HB, Cook SD (1984) Proprioception of the knee joint. Paradoxical effect of training. Am J Phys Med 63 (4): 175-181

4. Barrack RL, Skinner HB, Buckley SL (1993) Joint laxity and proprioception in the knee. Phys Sportsmed 11:130-135

5. Barrack RL, Skinner HB, Cook SD, Haddad RJ Jr (1983) Effect of articular disease and total knee arthroplasty on knee jointposition sense. J Neurophysiol 50(3):684-687

6. Barrett DS, Cobb AG, Bentley G (1991) Joint proprioception in normal, osteoarthritic and replaced knees. J Bone Jt Surg Br 73 (1):53-56

7. Behse F, Buchthal F (1971) Normal sensory conduction in the nerves of the leg in man. J Neurol Neurosurg Psychiatry 34(4):404-414

8. Bolton CF, Winkelmann RK, Dyck PJ (1966) A quantitative study of Meissner's corpuscles in man. Neurology 16(1):1-9

9. Brown WF (1972) A method for estimating the number of motor units in thenar muscles and the changes in motor unit count with ageing. J Neurol Neurosurg Psychiatry 35(6):845-852

10. Bruce MF, Sinclair DC (1980) The relationship between tactile thresholds and histology in the human finger. J Neurol Neurosurg Psychiatry 43(3):235-242

11. Bullock-Saxton JE, Wong WJ, Hogan N (2001) The influence of age on weight-bearing joint reposition sense of the knee. Exp Brain Res 136(3):400-406

12. Burke JR, Schutten MC, Koceja DM, Kamen G (1996) Agedependent effects of muscle vibration and the Jendrassik maneuver on the patellar tendon reflex response. Arch Phys Med Rehabil 77(6):600-604

13. Camicioli R, Panzer VP, Kaye J (1997) Balance in the healthy elderly: posturography and clinical assessment. Arch Neurol 54 (8):976-981

14. Campbell MJ, McComas AJ, Petito F (1973) Physiological changes in ageing muscles. J Neurol Neurosurg Psychiatry 36 (2):174-182 
15. Carpenter JE, Blasier RB, Pellizzon GG (1998) The effects of muscle fatigue on shoulder joint position sense. Am J Sports Med 26(2):262-265

16. Cauna N, Mannan G (1958) The structure of human digital pacinian corpuscles (corpus cula lamellosa) and its functional significance. J Anat 92(1):1-20

17. Colledge NR, Cantley P, Peaston I, Brash H, Lewis S, Wilson JA (1994) Ageing and balance: the measurement of spontaneous sway by posturography. Gerontology 40(5):273-278

18. De-Doncker L, Picquet F, Browne GB, Falempin M (2002) Expression of myosin heavy chain isoforms along intrafusal fibers of rat soleus muscle spindles after 14 days of hindlimb unloading. J Histochem Cytochem 50(11):1543-1554

19. Ferrell WR, Crighton A, Sturrock RD (1992) Age-dependent changes in position sense in human proximal interphalangeal joints. Neuroreport 3(3):259-261

20. Gauchard GC, Jeandel C, Tessier A, Perrin PP (1999) Beneficial effect of proprioceptive physical activities on balance control in elderly human subjects. Neurosci Lett 273(2):81-84

21. Ghez C, Sainburg R (1995) Proprioceptive control of interjoint coordination. Can J Physiol Pharmacol 73(2):273-284

22. Ghez C, Gordon J, Ghilardi MF (1995) Impairments of reaching movements in patients without proprioception. II. Effects of visual information on accuracy. J Neurophysiol 73(1):361-372

23. Gilsing MG, Van den Bosch CG, Lee SG, Ashton-Miller JA, Alexander NB, Schultz AB, Ericson WA (1995) Association of age with the threshold for detecting ankle inversion and eversion in upright stance. Age Ageing 24(1):58-66

24. Hashizume K, Kanda K (1995) Differential effects of aging on motoneurons and peripheral nerves innervating the hindlimb and forelimb muscles of rats. Neurosci Res 22(2):189-196

25. Hiemstra LA, Lo IK, Fowler PJ (2001) Effect of fatigue on knee proprioception: implications for dynamic stabilization. J Orthop Sports Phys Ther 31(10):598-605

26. Horak FB, Shupert CL, Mirka A (1989) Components of postural dyscontrol in the elderly: a review. Neurobiol Aging 10(6):727738

27. Hurley MV, Rees J, Newham DJ (1998) Quadriceps function, proprioceptive acuity and functional performance in healthy young, middle-aged and elderly subjects. Age Ageing 27(1):5562

28. Hutton RS, Atwater SW (1992) Acute and chronic adaptations of muscle proprioceptors in response to increased use. Sports Med 14(6):406-421

29. Iwasaki T, Goto N, Goto J, Ezure H, Moriyama H (2003) The aging of human Meissner's corpuscles as evidenced by parallel sectioning. Okajimas Folia Anat Jpn 79(6):185-189

30. Kaplan FS, Nixon JE, Reitz M, Rindfleish L, Tucker J (1985) Age-related changes in proprioception and sensation of joint position. Acta Orthop Scand 56(1):72-74

31. Kararizou E, Manta P, Kalfakis N, Vassilopoulos D (2005) Morphometric study of the human muscle spindle. Anal Quant Cytol Histol 27(1):1-4

32. Kokmen E, Bossemeyer RW Jr, Williams WJ (1978) Quantitative evaluation of joint motion sensation in an aging population. $\mathrm{J}$ Gerontol 33(1):62-67

33. Liu JX, Eriksson PO, Thornell LE, Pedrosa-Domellof F (2005) Fiber content and myosin heavy chain composition of muscle spindles in aged human biceps brachii. J Histochem Cytochem 53 (4):445-454

34. Lord SR, Ward JA (1994) Age-associated differences in sensorimotor function and balance in community dwelling women. Age Ageing 23(6):452-460

35. Lord SR, Rogers MW, Howland A, Fitzpatrick R (1999) Lateral stability, sensorimotor function and falls in older people. J Am Geriatr Soc 47(9):1077-1081
36. Manchester D, Woollacott M, Zederbauer-Hylton N, Marin O (1989) Visual, vestibular and somatosensory contributions to balance control in the older adult. J Gerontol 44(4):M118-M127

37. Marks R, Quinney HA, Wessel J (1993) Proprioceptive sensibility in women with normal and osteoarthritic knee joints. Clin Rheumatol 12(2):170-175

38. Masliah E, Mallory M, Hansen L, DeTeresa R, Terry RD (1993) Quantitative synaptic alterations in the human neocortex during normal aging. Neurology 43(1):192-197

39. McCloskey DI (1978) Kinesthetic sensibility. Physiol Rev 58 (4):763-820

40. McComas AJ (1995) Motor unit estimation: anxieties and achievements. Muscle Nerve 18(4):369-379

41. Meeuwsen HJ, Sawicki TM, Stelmach GE (1993) Improved foot position sense as a result of repetitions in older adults. J Gerontol 48(3):P137-P141

42. Mion LC, Gregor S, Buettner M, Chwirchak D, Lee O, Paras W (1989) Falls in the rehabilitation setting: incidence and characteristics. Rehabil Nurs 14(1):17-22

43. Miwa T, Miwa Y, Kanda K (1995) Dynamic and static sensitivities of muscle spindle primary endings in aged rats to ramp stretch. Neurosci Lett 201(2):179-182

44. Monster AW, Herman R, Altland NR (1973) Effect of the peripheral and central "sensory" component in the calibration of position. In: Desmedt JE (ed) New developments in electromyography and clinical neurophysiology. Krager, Basel, pp 383403

45. Morisawa Y (1998) Morphological study of mechanoreceptors on the coracoacromial ligament. J Orthop Sci 3(2):102-110

46. Mynark RG, Koceja DM (2001) Effects of age on the spinal stretch reflex. J Appl Biomech 17(3):188-203

47. Nakamura S, Akiguchi I, Kameyama M, Mizuno N (1985) Agerelated changes of pyramidal cell basal dendrites in layers III and $\mathrm{V}$ of human motor cortex: a quantitative Golgi study. Acta Neuropathol (Berl) 65(3-4):281-284

48. Overstall PW, Exton-Smith AN, Imms FJ, Johnson AL (1977) Falls in the elderly related to postural imbalance. Br Med J 1 (6056):261-264

49. Pai YC, Rymer WZ, Chang RW, Sharma L (1997) Effect of age and osteoarthritis on knee proprioception. Arthritis Rheum 40 (12):2260-2265

50. Pakkenberg B, Gundersen HJ (1997) Neocortical neuron number in humans: effect of sex and age. J Comp Neurol 384(2)1: $312-320$

51. Petrella RJ, Lattanzio PJ, Nelson MG (1997) Effect of age and activity on knee joint proprioception. Am J Phys Med Rehabil 76 (3):235-241

52. Pickard CM, Sullivan PE, Allison GT, Singer KP (2003) Is there a difference in hip joint position sense between young and older groups? J Gerontol A Biol Sci Med Sci 58(7):631-635

53. Proske U (2005) What is the role of muscle receptors in proprioception? Muscle Nerve 31(6):780-787

54. Proske U, Wise AK, Gregory JE (2000) The role of muscle receptors in the detection of movements. Prog Neurobiol 60 (1):85-96

55. Robbins S, Waked E, McClaran J (1995) Proprioception and stability: foot position awareness as a function of age and footwear. Age Ageing 24(1):67-72

56. Roll JP, Hay L, Quoniam C, Roll R (1992) Muscle proprioception: a powerful sensory input for postural adaptation in man. In: Vellas B, Toupet M, Rubenstein L, Albarede JJ, Christen Y (eds) Falls, balance and gait disorders in the elderly. Elsevier, Paris, pp161182

57. Rozzi S, Yuktananandan P, Pincevero D, Lephart SM (2000) Role of fatigue on proprioception and neuromuscular control. In: Lephart SM, Fu FH (eds) Proprioception and neuromuscular 
control in joint stability. Human Kinetics, Champaign, IL, pp375384

58. Scheibel ME, Lindsay RD, Tomiyasu U, Scheibel AB (1975) Progressive dendritic changes in aging human cortex. Exp Neurol 47(3):392-403

59. Sharma AK, Bajada S, Thomas PK (1980) Age changes in the tibial and plantar nerves of the rat. J Anat 130(Pt 2):417-428

60. Sherrington CS (1906) The integrative action of the nervous system. Yale University Press, New Haven, CT, USA

61. Shumway-Cook A, Woollacott M (2001) Motor control: theory and practical applications. Williams \& Wilkins, Baltimore

62. Skinner HB (1993) Pathokinesiology and total joint arthroplasty. Clin Orthop Relat Res 288:78-86

63. Skinner HB, Barrack RL, Cook SD (1984) Age-related decline in proprioception. Clin Orthop Relat Res 184:208-211

64. Sorock GS, Labiner DM (1992) Peripheral neuromuscular dysfunction and falls in an elderly cohort. Am J Epidemiol 136 (5):584-591

65. Stalberg E (1982) Macroelectromyography in reinnervation. Muscle Nerve 5(9S):S135-S138

66. Stalberg E, Borges O, Ericsson M, Essen-Gustavsson B, Fawcett PR, Nordesjo LO, Nordgren B, Uhlin R (1989) The quadriceps femoris muscle in 20-70-year-old subjects: relationship between knee extension torque, electrophysiological parameters, and muscle fiber characteristics. Muscle Nerve 12(5):382-389

67. Stelmach GE, Sirica A (1986) Aging and proprioception. Age 9 (4):99-103

68. Strong R (1998) Neurochemical changes in the aging human brain: implications for behavioral impairment and neurodegenerative disease. Geriatrics 53(1):S9-S12

69. Swash M, Fox KP (1972) The effect of age on human skeletal muscle. Studies of the morphology and innervation of muscle spindles. J Neurol Sci 16(4):417-432

70. Tanosaki M, Ozaki I, Shimamura H, Baba M, Matsunaga M (1999) Effects of aging on central conduction in somatosensory evoked potentials: evaluation of onset versus peak methods. Clin Neurophysiol 110(12):2094-2103
71. Thelen DG, Brockmiller C, Ashton-Miller JA, Schultz AB, Alexander NB (1998) Thresholds for sensing foot dorsi- and plantarflexion during upright stance: effects of age and velocity. J Gerontol A Biol Sci Med Sci 53(1):M33-M38

72. Tinetti ME, Speechley M, Ginter SF (1988) Risk factors for falls among elderly persons living in the community. N Engl J Med 319(26):1701-1707

73. Tsang WW, Hui-Chan CW (2003) Effects of tai chi on joint proprioception and stability limits in elderly subjects. Med Sci Sports Exerc 35(12):1962-1971

74. Verdu E, Ceballos D, Vilches JJ, Navarro X (2000) Influence of aging on peripheral nerve function and regeneration. J Peripher Nerv Syst 5(4):191-208

75. Verrillo RT (1979) Change in vibrotactile thresholds as a function of age. Sens Process 3(1):49-59

76. Verschueren SM, Brumagne S, Swinnen SP, Cordo PJ (2002) The effect of aging on dynamic position sense at the ankle. Behav Brain Res 136(2):593-603

77. Voight ML, Hardin JA, Blackburn TA, Tippett S, Canner GC (1996) The effects of muscle fatigue on and the relationship of arm dominance to shoulder proprioception. J Orthop Sports Phys Ther 23(6):348-352

78. Walro JM, Wang J, Story GM (1997) Afferent-inherent regulation of myosin heavy chain isoforms in rat muscle spindles. Muscle Nerve 20(12):1549-1560

79. Wang J, McWhorter DL, Walro JM (1997) Stability of myosin heavy chain isoforms in selectively denervated adult rat muscle spindles. Anat Rec 249(1):32-43

80. Woollacott MH, Shumway-Cook A, Nashner LM (1986) Aging and posture control: changes in sensory organization and muscular coordination. Int J Aging Hum Dev 23(2):97-114

81. Yan T, Hui-Chan CW (2000) The ability to detect movement of the knee joint is decreased with aging. Arch Phys Med Rehabil $81: 1274$

82. You SH (2005) Joint position sense in elderly fallers: a preliminary investigation of the validity and reliability of the SENSERite measure. Arch Phys Med Rehabil 86(2):346-352 